\title{
ORGANIC-INORGANIC HYBRID MATERIALS PROCESSING AND APPLICATIONS
}

\author{
H.K. SCHMIDT, M. MENNIG, R. NONNINGER, P.W. OLIVEIRA, H. SCHIRRA \\ Institut fuer Neue Materialien gem. GmbH, Im Stadtwald, Bldg. 43 A, D-66 123 \\ Saarbruecken, Germany, schmidt@inm-gmbh.de
}

\begin{abstract}
Hybrid materials as inorganic-organic nanostructured composites require tailored surface chemistry in order to obtain a homogeneous distribution of the nanoparticles in the matrix. For this reason, nanoparticles with organic functions have been synthesized, first, to provide the desired $\zeta$-potential at a given $\mathrm{pH}$ value, second, to avoid irreversible agglomeration due to the spacing effect, and third, to provide the appropriate surface chemistry. I could be shown that using this approach, it is possible to switch the $\zeta$-potential of $\mathrm{SiO}_{2}$ nanoparticles from a negative to a positive potential at neutral and to bind DNA fragments to the particles for an effective transfection into cells. Other examples show that nanoparticles $\left(\mathrm{TiO}_{2}, \mathrm{SiO}_{2}\right)$ coated with epoxy and methacryloxy groupings can be used as coating sol for the fabrication of thin films with green densities up to $67 \%$ by volume only by photochemical crosslinking of the polymerizable groupings. Using this approach, interference layers have been fabricated on transparent plastics. In soft matrices, these particles permit to establish appropriate $\zeta$-potentials and in electric fields by electrophoresis, it was possible to up-concentrate them to form gradient index optics. The investigations show that surface chemistry-tailored nanoparticles are a useful tool for the fabrication of nanocomposite hybrids.
\end{abstract}

\section{INTRODUCTION}

Inorganic-organic hybrid materials synthesized by the sol-gel process have gained high importance during the last fifteen years. First interesting industrial applications have been reported for transparent scratch-resistant coatings [1]. Many papers have been published with very special functions such as glazing systems $[2,3,4,5]$. The vast majority of hybrid materials are based on organofunctional silanes, which contribute to the inorganic backbone and at the same time play the role as a carrier of organic functions. Materials based on this approach are ORMOSILs [6]. The use of reactive groupings in organofunctional silanes (epoxides, methacrylates, amines in connection with epoxides or anhydrides) leads to an additional crosslinking, and the formation of inorganic as well as organic backbones at the same time [7].

The use of alkoxides of elements outside Si (alumina, zirconia, titania) in combination with silanes may lead to different levels of "inhomogeneity" or phase separation depending on the processing routes. There are hints that the level of phase separation is very low, close to the molecular or oligomeric state [8], but it is also indicated that the phase separation may reach the nano level $[9,10]$. The vast majority of this literature is devoted either to mechanisms of molecular chemical reactions (mainly investigated by NMR) or materials properties such as mechanical properties $[11,12,13,14]$ or functional properties. Surprisingly low attention is paid to the colloidal part of these systems which always play an important role if phase separation to particulate systems takes place. In these cases, surfaces and interfaces are created which have specific properties. Especially surface charges, which, in general, occur as a function of the $\mathrm{pH}$ value, or surface modification by reacting the colloid particle surface with 
desired compounds to create specific surface properties are of importance. For this reason, the present paper will summarize some important features related to surface and colloidal chemistry and its effect on processing routes and hybrid materials properties.

\section{GENERAL CONSIDERATIONS AND RESULTS}

As described in detail elsewhere [15] and known from the state of the art of colloidal chemistry, small particles such as sol particles have to be stabilized in order to prevent agglomeration. The stabilization by electric charges, which is the usual type of stabilization, is described by Stern's model [16] and shows that the repulsion potential is a function of the particle-to-particle distance and the electric charge of the particle. A rough measure for the electric charge density on the surface is the so-called $\zeta$-potential. Stern's model also shows that if the distance between two particles becomes smaller than the critical distance, the repulsion changes into attraction. If the particles attract each other, a variety of different bonding mechanisms depending on the chemical surface properties are activated (e.g. van der Waals forces, hydrogen bonds, chemical bonds, complex bonds etc.), leading to a more or less strong solidification of the liquid (gel formation). The Stern's mechanism of gelation is widely used in solgel coating technologies where the gelation takes place by solvent evaporation, followed by an up-concentration and a reduction of the particle-to-particle distance below the critical distance. The main drawback of the charge stabilization in sol-gel systems is the fact that the electric potential is depending on the $\mathrm{pH}$ value. This is a very limiting restriction, especially if the nanoparticles will be used, for example, for dispersing them into other matrix systems. A second drawback is that, as an effect of the surface chemistry, for many systems $\mathrm{pH}$ values outside of neutral have to be chosen for obtaining sufficient high $\zeta$-potentials. A third drawback is that if mixtures are prepared having $\zeta$-potentials at a given $\mathrm{pH}$ with different $(+,-)$ signs, for example for multicomponent systems, no system stability can be obtained due to hetero coagulation. For these cases, it seems to be very desirable to produce sols or nanodispersed suspensions with tailorable $\zeta$-potentials, which open the perspective for important processing advantages. In fig. 1, two examples for surface tailoring are given, $\mathrm{TiO}_{2}$ and $\mathrm{ZrO}_{2}$.

The synthesis of the surface-modified $\mathrm{TiO}_{2}$ or $\mathrm{ZrO}_{2}$ sols was carried out by mixing $10 \mathrm{~g}$ nanoscaled $\mathrm{TiO}_{2}$ prepared according to [17] and $2.2 \mathrm{~g} \mathrm{GF} 20\left(\mathrm{Et}_{3} \mathrm{OSi}\left(\mathrm{CH}_{2}\right)_{3} \mathrm{CH}\left(\mathrm{CCH}_{2}\right) \mathrm{C}_{2} \mathrm{O}_{3}\right)$,

$$
(\mathrm{OEt})_{3}-\mathrm{Si}-\left(\mathrm{CH}_{2}\right)_{3}-\underset{\mathrm{H}}{\mathrm{C}}-\stackrel{\mathrm{C}}{=}=\mathrm{O}
$$
rsp. $1.6 \mathrm{~g} \mathrm{AEA}\left(\mathrm{Me}_{3} \mathrm{OSi}\left(\mathrm{CH}_{2}\right)_{3} \mathrm{NH}\left(\mathrm{CH}_{2}\right)_{2} \mathrm{NH}_{2}\right)$, or $0.72 \mathrm{~g}$ acac as surface modificator in $300 \mathrm{ml}$ toluole. After boiling for 2 hours, the modified powder can be separated by filtration, followed by washing in toluole and drying for 16 hours and $50{ }^{\circ} \mathrm{C}$. This shows clearly that the $\zeta$-potential is strongly depending on the surface modification and that it is possible to prepare stable sols at neutral. In the case of $\mathrm{ZrO}_{2} / \mathrm{acac}$, a very flat curve is obtained. This means that the interaction of the surface with protons or hydroxides can be very important if industrial coating techniques are built up where acids may lead to contamination or corrosion problems.

The tailoring of the $\zeta$-potential is very important for the technical use of sols, for example, for coatings. So in many cases, technically used sols are proton-stabilized, that means a sufficient high $\zeta$-potential is obtained by the addition of sufficient volatile strong acid. The removal of acids during the process of drying and curing, in many cases, leads to serious problems related to corrosion of equipment. A second drawback of the acid stabilization is the fact that these sols, in general, despite the stabilization, are ageing. The aging process can be attributed to effects, one caused by the high 

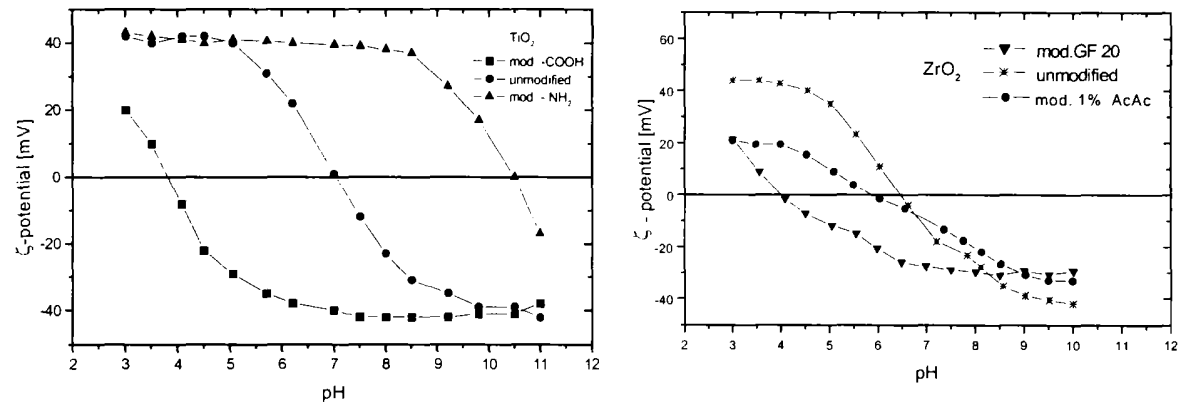

Fig. 1a: $\zeta$-potential of $\mathrm{TiO}_{2}$ sols without and with acid and basic surface modifiers; b: $\mathrm{ZrO}_{2}$ without and with GF20 (the anhydride reacts to the acid).

energetic fraction of the particle motion which may lead to condensation of particles if they are approaching each other by breaking through the Stern barrier. This is very dependent on the particles' concentration. The second is an Ostwald ripening process which is caused by the solubility of the particles, which, in general, is not zero for most cases of oxides in acid solutions (alcohols or water/alcohol mixtures).

As shown elsewhere [18], the $\zeta$-potential for $\mathrm{SiO}_{2}$ can be shifted from positive to negative values by appropriate choice of type and amount of surface modification with amino silanes. Similar results have been obtained with silicon carbide particle surfaces, too, since they, in general, are covered by a layer of $\mathrm{SiO}_{2}$. In fig. 2 silicon carbide and $\mathrm{SiO}_{2}$ particles with different $\zeta$-potential curves are shown. As one can see clearly, the amino groupings shift the

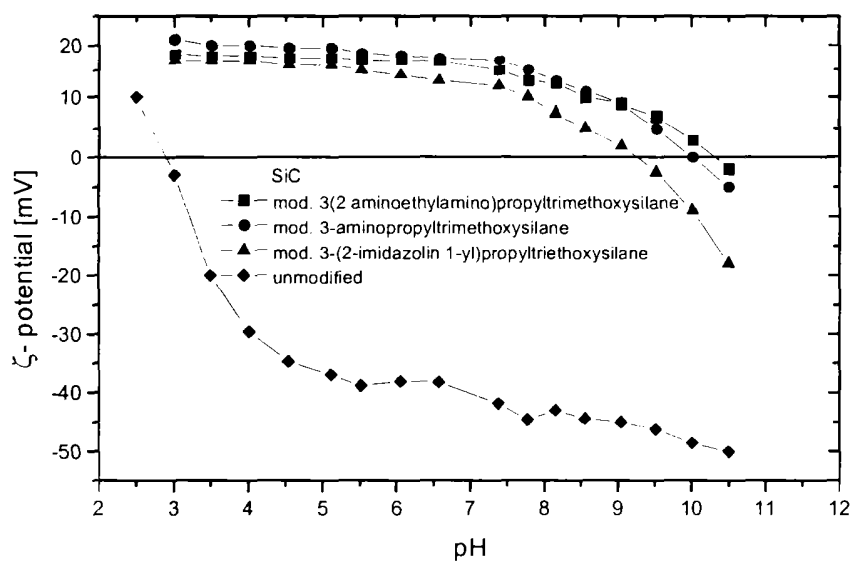

Fig. 2: Comparison of the $\zeta$-potential of an unmodified SiC particle surface with amino grouping modified particles.

potentials to positive values, as expected, but there is no significant difference between the different amines.

Another important requirement comes from biological systems which may advantageously be combined with nanoparticles, for example, as carriers for biological molecules. For the adsorption of DNA, for example, in many cases positive surface charges are used. If that has to be combined with non-toxic particles, for example, $\mathrm{SiO}_{2}$, the $\mathrm{SiO}_{2} \zeta$-potential has to be positive in the neutral, which is not the case with colloidal silica. As shown elsewhere, the surface modification of $\mathrm{SiO}_{2}$ with amino groups can be used for tailoring the $\zeta$-potential in the right way. 
The use of non-condensable surface groupings which only partly cover the surface of the particle has many advantages, as it is shown in fig. 3. The first advantage is that, due to the
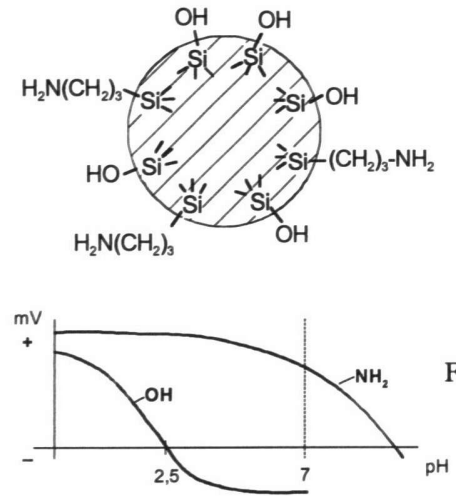

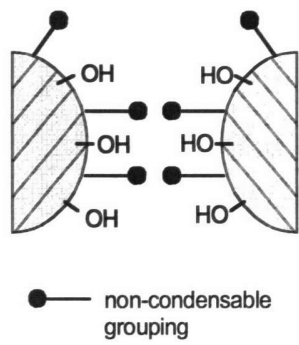

Fig. 3: Principles and advantages of surface modification of colloidal particles by non-condensable groupings

Fig. 3: Principles and advantages of surface modification of colloidal particles by non-condensable groupings.

ionic character of the surface modifiers, the $\zeta$-potential can be changed in the desired direction (electrosteric stabilization). Second, the groups can act as spacers, preventing the condensation reaction between particles, even if the critical distance of the Stern's potential is violated. In this case, only van der Waals' forces may be active, which, of course, can easily be overcome by appropriate solvent conditions.

For appropriate surface modifications, a large variety of different routes are available, and almost any type of bond can be used (for example, covalent bonds, ionic bonds, complex bonds, hydrogene bonds and polar interactions). It is important that the contribution of the surface modifier to the total volume remains small if the nanoparticles should not be a very small fraction of the total volume. This means that it is necessary to use small molecules which, in opposition to polymeric molecules have to be fixed very strongly to the surface.

The effect of surface modification for $\zeta$-potential tailoring is given in the following example: In order to bind DNA fragments to the surface of small particles, it is necessary to provide positive surface charges.

For the fabrication of the modified particles, the following procedures have been used: $100 \mathrm{ml}$ of an aqueous silica particle suspensicn (5 wt.-\%) was added to a solution of $15 \mathrm{ml}$ acetic acid in $75 \mathrm{ml}$ ethylenglykol. After the addition of 1 (for partial modification) or $100 \mathrm{wt} . \%$ (complete modification) of the silanes as described in fig. 4, the mixture was stirred for $16 \mathrm{~h}$ at $80^{\circ} \mathrm{C}$. Water and acetic acid were distilled of and the resulting glycolic suspension was dialyzed against deionized water. For the methylation of the aminosilane particle surface, $7.5 \mathrm{ml}$ of the glycolic suspension was stirred with $4 \mathrm{~g} \mathrm{CH}_{3} \mathrm{I}$ for $24 \mathrm{~h}$ at room temperature. The excess of $\mathrm{CH}_{3} \mathrm{I}$ was reacted with ammonia and the suspension was dialyzed against deionized water.

As known from literature [19], positively charged surfaces are necessary in order to bind DNA fragments in a way that the DNA chains are fixed in a stabilized, that means in a condensed form. This is due to the fact that DNA is an anionic biopolymer, where each monomer of the nucleic acid carries a negative charge under physiological conditions $(\mathrm{pH} 7.2)$ which lead to an extensive structure of the polynucleotide by electrostatic repulsion. The high charge, the physical and enzymatical instability makes the direct use of such DNA under in vitro or in vivo conditions impossible. The use of polynucleotide under such conditions requires their protection and their transfer into a transportable form. The negative charges must be compensated to bring the DNA molecule into the required condensed form, which is accompanied by a remarkable reduction of the diameter from several $\mu \mathrm{m}$ to less than $200 \mathrm{~nm}$. This is of great importance for 
the transfection of the DNA into cells. If these particles were mixed with plasmid DNA

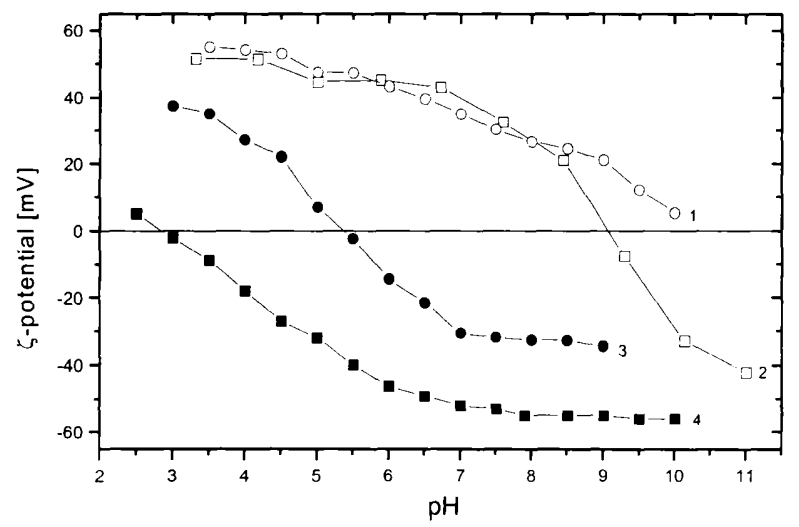

Fig. 4: $\zeta$-potential curves of various $10-\mathrm{nm} \mathrm{SiO}_{2}$ particles in aqueous solutions; 1 :N-aminohexyl aminopropyl triethoxysilane modified $\mathrm{SiO}_{2} ; 2: \mathrm{SiO}_{2}$ particles completely modified with $\gamma$-aminopropyl triethoxysilane (10 mg APS $/ 1 \mathrm{~g}$ Silica); $3: \mathrm{SiO}_{2}$ particles partially modified with $\gamma$-aminopropyl triethoxysilane; 4: unmodified $\mathrm{SiO}_{2}$ particles [20].

(pCMV $\beta$ ), a strong electrostatic interaction between the two polyions occured. At a wt.-ratio of 30:1 DNA-particle-complexes resulted with a mean hydrodynamic complex diameter of $180 \mathrm{~nm}$, while the dimension of uncomplexed DNA is in the upper $\mu \mathrm{m}$ range. These complexes were used to test transfection in vitro with Cos-1 cells. The expression of $\beta$-galactosidase, which was detected by fluorescence, indicated a successful transfection. As one can see from fig. 4 , the $\mathrm{pH}$ can be varied between 4 and 8.5 with $\zeta$-potentials not below $\pm 20 \mathrm{mV}$. For the immobilization of DNA fragments, the type 1 was chosen, since at $\mathrm{pH} 7.2$, the $\zeta$-potential is in the range of $+50 \mathrm{mV}$, a value which was considered to be sufficient for the DNA stabilization as well as for the particle stabilization at neutral. As shown elsewhere, inorganic surface modified nanoparticles are also suitable systems for the binding and condensation of DNA [21]. In fig. 4, the effect of different types of surface modifying on the $\zeta$-potential is shown. The transfection efficiency at the present state of the development was only about $30 \%$ in comparison to established DNA carrier systems like polyethylenimin. But the inorganic carrier system possessed only one hundredth of the cytotoxicity of the organic polymer. These new carrier systems based on inorganic nanoparticles were called nanoplexes.

Another example for a material development making use of the $\zeta$-potential tailoring is the development of high-grade SSiC, as described elsewhere [22]. In this case, as shown in fig. 2 , the surface was modified by ammines according to the following procedure: The sub- $\mu \mathrm{m} \mathrm{SiC}$ powders were dispersed in water with acetic acid at $\mathrm{pH} 2.5$. After addition of the silane (according to fig. 2), the slurry was stirred for 2 hours at $100{ }^{\circ} \mathrm{C}$. After this, the $\mathrm{pH}$ was raised to 11 with tetra methyl ammonium hydroxide (TMAH), filtered, washed and dried for $16 \mathrm{hrs}$ at $130^{\circ} \mathrm{C}$. These powders then have been either reacted with $\mathrm{COOH}$-group containing carbon black by refluxing in toluene ( $\mathrm{pH}$-independent $\mathrm{C}$ coating) or electrostatically coated with carbon black ( $\mathrm{pH}$ dependent coating) (fig. 5). With both methods, very homogeneous green bodies can be obtained [23] to be pressurelessly sintered to nearnet shape green bodies. It could be demonstrated [22] that large silicon carbide parts can be obtained by simple pressureless sintering with a very high quality. Generalizing, it is to say that by the formation of nanohybrid particles, 


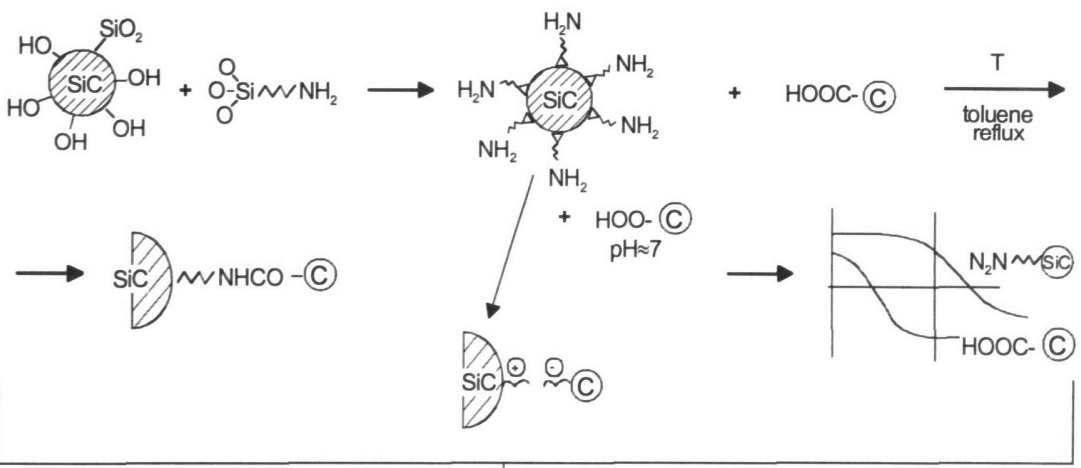

(C) = carbon black

Fig. 5: Schematics of two routes for carbon black coatings for $\mathrm{SiC}$ and SEM micrograph showing carbon black particles on top of SiC.

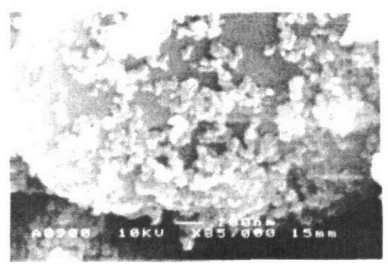

the surface charge of the particles can be tailored in a very wide range and that interesting advantages with respect to processing these particles to materials can be obtained. This leads to an interesting strategy, to a so-called multilevel hybrid system where, for example, the range of hybridization is on a molecular, on a nano-scale and on a microscopic scale. This is shown schematically in fig. 6, and in addition to this, a model of a 3-level boehmite nanocomposite.

Based on this concept, interesting material properties seem to be possible. Whereas in the molecular range of hybridization the structure-related properties are the most important, this type of systems (Ormosils, Ormocers) show, for example, very hard properties [1] or elastic properties [6], and many interesting applications, especially in the field of coatings are under development or already used. However, it is not possible to take benefit of the solid state properties of the inorganic phase as far as it is not the ionic state. If one reaches the second level of a hybrid system that means in the nano-scale system, the solid state physical properties of nanoparticles also can be used for materials tailoring. This is shown schematically in fig. 6 .
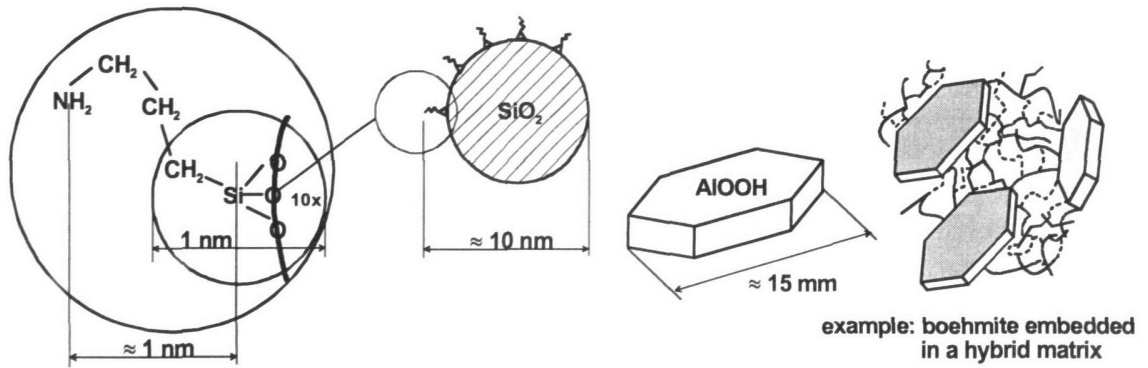

Fig. 6: Model of $\mathrm{SiO}_{2}$ and $\mathrm{AlOOH}$ multilevel hybrids. 
There are many interesting properties related to nanoparticles such as quantum size effects, large surface area, catalytic effects or effects of the change of properties with size. Moreover, if the particle size is small enough, Rayleigh scattering can be neglected, and interesting systems for many optical applications become possible by making use of the solid state properties of the nanoparticles. One of the prerequirements for sufficient optical properties is a perfect dispersion of nanoparticles in matrices (polymeric or molecular hybrid matrices). In this case, it is difficult to use conventional compounding techniques since the forces "attaching" nanoparticles by shear, in general, are far too low in such processes.

\section{MATERIAL DEVELOPMENT EXAMPLES BASED ON SURFACE MODIFICATION AND $\zeta$-POTENTIAL TAILORING}

\section{Basics of graded index materials fabrication}

The graded index materials fabrication is an interesting approach by using nanoparticles which have a refractive index different from the matrix systems. In order to receive refractive index gradients, the nanoparticles have to be up-concentrated to obtain a desired distribution profile. In this case, different ways can be suggested. It is possible to form chemical potentials by "consuming" nanoparticles by chemical reactions as is already shown by the fabrication of nanoparticle-based holograms through two-wave mixing [24]. The chemical potential in these cases was obtained by coating the particles with polymerizable ligands and by photopolymerizing them by UV light. Since the photopolymerized particles are different from the unpolymerized, the unpolymerized ones tend to diffuse into the areas where the photopolymerization takes place and, thus, increase the concentrations and, subsequently, the refractive index. Another possibility, as basically shown elsewhere [25], is to up-concentrate charged nanoparticles in a not fully densified polymer or ormocer matrix by electrophoresis and to immobilize the particles after up-concentration by polymerization. For this purpose, the particles have to carry surface charges and at the same time polymerizable or polycondensable ligands (for example, methacrylic acid on $\mathrm{ZrO}_{2}$ ). The basic approach is shown in fig. 7. For high refractive index

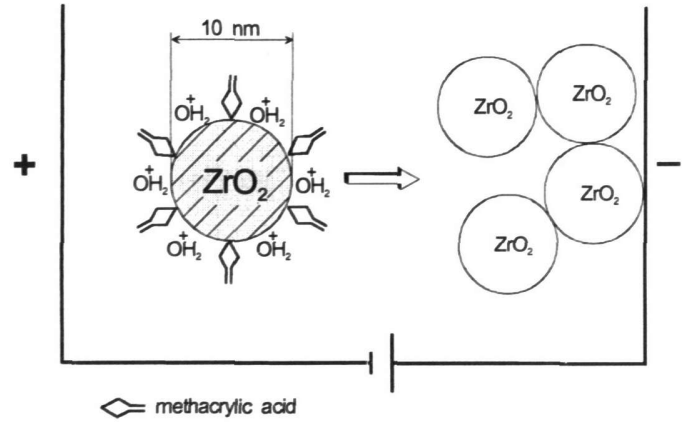

Fig. 7: Electrophoretic movement of $\mathrm{ZrO}_{2}$ nanoparticles in an electric field under acid conditions.

particles, zirconia particles were chosen, since, as shown elsewhere [26], zirconia particles can easily be surfacemodified by methacrylic acid, and they can, as also shown elsewhere [27] be densified to crystalline zirconia nanoparticles at temperatures below $120^{\circ} \mathrm{C}$, still having methacrylic acid molecules

bonded to the surface. Since it is unlikely that the zirconia surface is completely covered with methacrylic acid (acid conditions) and due to the fact that methacrylic acid is bonded to the surface and has a partially ionic character, it can be anticipated that the surface charge can easily be influenced by $\mathrm{pH}$ variation.

$\mathrm{SiO}_{2}$ in opposition to zirconia has a rather low refractive index around 1.45. It is of interest to investigate how far $\mathrm{SiO}_{2}$ nanoparticles can be obtained showing the opposite $\zeta$-potential at the 
given $\mathrm{pH}$ value. Due to the $\mathrm{SiO}_{2}$ surface chemistry, methacrylic acid can be used as surface modifier. For this reason, epoxysilanes have been used to modify the particles' surface with a polymerizable ligand, in this case epoxy silane. It also can be anticipated that, due to the type of chemical bonds to the surface and the surface chemistry of the $\mathrm{SiO}_{2}$, an influence of the $\mathrm{pH}$ value on the surface charge can be possible. The $\zeta$-potential curves of the epoxy-modified $\mathrm{SiO}_{2}$ nanoparticles are shown in fig. 8. Comparing the $\zeta$-potential with $\mathrm{ZrO}_{2}, \mathrm{pH}$ ranges can be

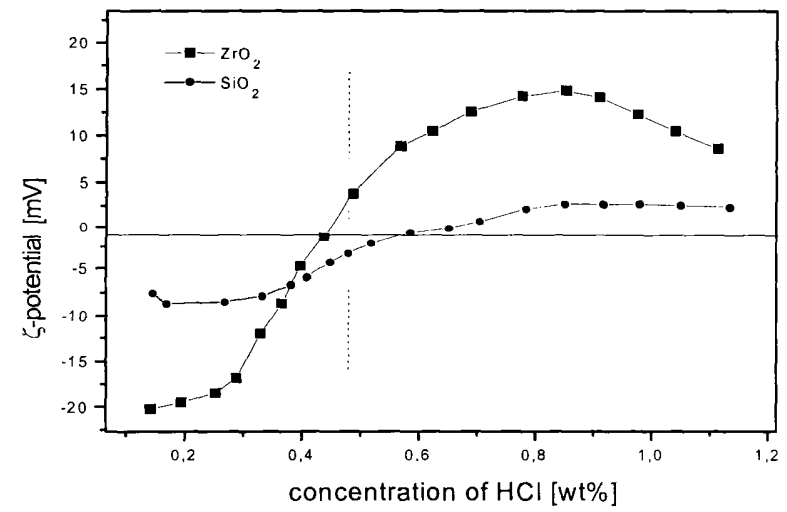

Fig. 8: $\zeta$-potential curves of $\mathrm{SiO}_{2}$ and $\mathrm{ZrO}_{2}$ nanoparticles in the acid regime; dashed line: chosen conditions for electrophoresis.

identified where $\mathrm{SiO}_{2}$ and zirconia show the opposite $\zeta$-potential. With the possibility of moving $\mathrm{SiO}_{2}$ and zirconia into the opposite direction, the differences of the refractive index could be increased. For testing the realizability of this idea, the nanoparticles $\mathrm{SiO}_{2}$ and zirconia are distributed in a glycidyloxypropyl triethoxysilane precondensate with sufficiently low viscosity, and an electric field has been employed for several hours [28]. After photocuring the system, an EDX line scan was carried out, which is shown in fig. 9, showing the distribution of zirconia and silica over a distance of $5 \mathrm{~mm}$. As one can clearly see, the $\mathrm{SiO}_{2}$ concentration reaches a minimum at a place where the zirconia reaches a maximum, showing that the hypothesis of counterelectrophoresis in order to increase refractive index steps basically works. For the technical realization, further investigations and developments are necessary.

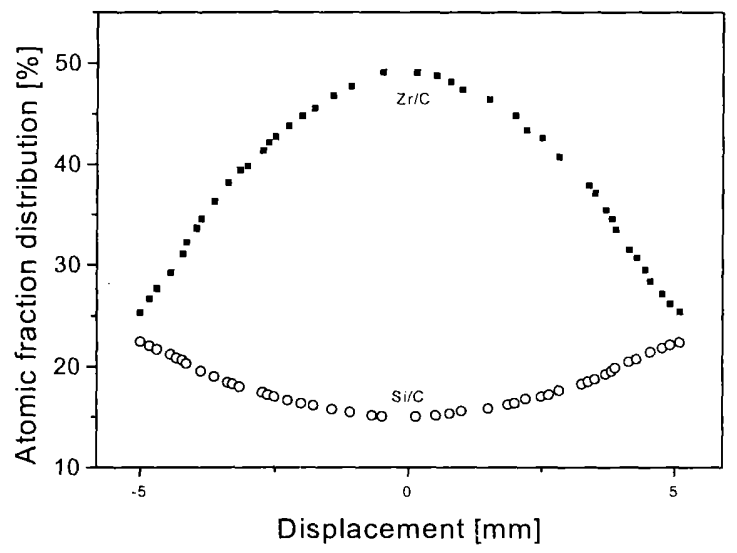

Fig. 9: Atomic fraction distributions of $\mathrm{Si}$ and $\mathrm{Zr}$ against carbon measured by EDX along the diameters, standardized by the $\mathrm{C}$ signal.

Another example for the use of surface modification is the application of surface-modified polymerizable $\mathrm{SiO}_{2}$ modified with methacryloxy silanes and $\mathrm{TiO}_{2}$ surface-modified with epoxy silanes. The surface modification with methacryloxy silanes leads to colored products, probably

due to olefinic complex formation on titanium alkoxides. This is not the case if epoxy silanes are used. Dispersing both systems in appropriate matrix systems (in alcoholic solutions: isopropanol, rsp. ethanol with methacrylic acid [29]), coating liquids can be obtained. Solutions containing $\mathrm{SiO}_{2}$ nanoparticles can be prepared by an alcoholic solution with $30 \mathrm{wt} \% \mathrm{SiO}_{2}$ 
prepared by acid hydrolysis and condensation of TEOS (tetraethoxysilane), stabilized with 0.5 wt $\%$ glucose. Finally GPTS (3-glycicdoxypropyltrimethoxysilane) has to be added in the weight ratio of $\mathrm{SiO}_{2} / \mathrm{GPTS}=4: 1$.

$\mathrm{TiO}_{2}$ containing solutions can be synthesized by adding tetraisopropylorthotitanate $(2.1 \mathrm{~g})$ to an acid mixture of isopropanol $(0.981 \mathrm{~g})$ and water $(0.205 \mathrm{~g})$. After stirring for 24 hours at $25^{\circ} \mathrm{C}$, $2 \mathrm{~g}$ GPTS must be added, and $10 \mathrm{~g}$ isopropanol have to be removed and $14 \mathrm{~g}$ of 2 -isopropoxyethanol to be added [26]. These systems can be used as coating liquids for plastic and glass substrates. After coating and drying, the $\mathrm{SiO}_{2}$ or $\mathrm{TiO}_{2}$ content of the films is 61 or $67 \%$, respectively, by volume. This shows that a surprisingly high "green density“ can be obtained, leading to refractive indices of about 1.46 for the silica layer on glass and 1.92 for the $\mathrm{TiO}_{2}$ layer on PC. The schematics of the process is described in fig. 10. The difference in the

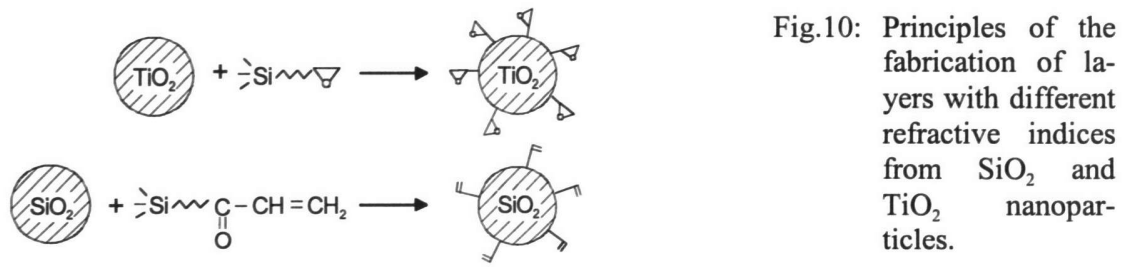

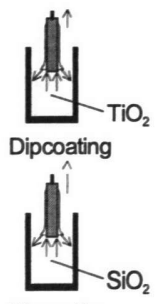

Dipcoating
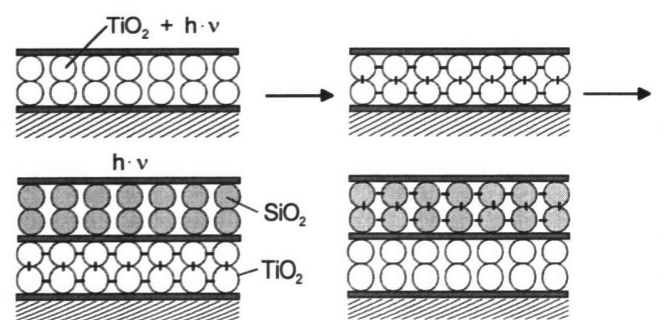

refractive index can be used for the fabrication of optical interference systems such as antireflective layers. For this case, two different routes, as described elsewhere $[29,30]$, can be performed. After each coating (dip or spray in optical quality), the sys-

tems can be either photopolymerized to transparent layers on plastic with reasonable scratch resistance or fired to inorganic layers on glass, ceramic or metals at $500^{\circ} \mathrm{C}$, in the case of heat resistant substrates, they can be fired in a one-step (stack) process to optical layers. In the case of firing, the refractive index of $\mathrm{SiO}_{2}$ is in the range of 1.45 and $\mathrm{TiO}_{2}$ in the range of 2.2 , in the unfired process 1.45 and 1.92, respectively. Based on this approach, different anti-reflective coatings have been fabricated [31].

The synthesis of optical materials using surface modified nanoparticles, in this case for reducing the interfacial free energy, also has been demonstrated with epoxy PMMA copolymer sealants for fiber-to-chip couplings using nanoparticles as fillers. In this case, as described elsewhere, the high amounts of fillers have to be used in order to reduce the thermal coefficient of expansion as well as the shrinkage of the seal during photocuring. For obtaining high optical transparency, nanoparticulate fillers had been used. So 6-nm-particles have been chosen. The details of the process are described elsewhere [32]. In fig. 11, the results of the viscosity measurements are shown. TMAH has been chosen, since, despite of the weak bond to $\equiv \mathrm{SiOH}$, it could be expected to obtain sufficient stability in non-aqueous MMA/epoxy monomer liquid. The viscosity of the mixture was expected to be a sensitive measure for the dispersion or particle-to-particle interaction. In fig. 11, the results of the viscosity measurements are shown. 


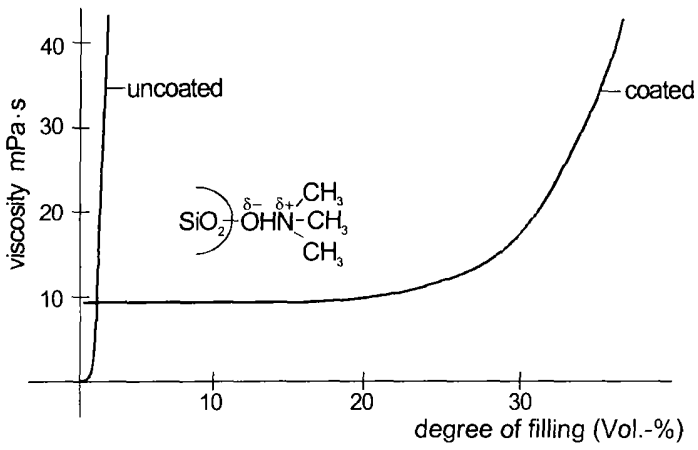

Fig. 11: Viscosity of uncoated and TMAH-coated particles as a function of the degree of filling.

As described elsewhere [32], the sealant can easily be cured without a disturbing shrinkage and, due to the nanoparticles, the thermoplastic material shows a rubbery plateau which maintains about $10 \%$ of the mechanical strength above the $T_{g}$ of $120^{\circ} \mathrm{C}$, which is sufficient for avoiding a misalignment of the fiber-to-chip coupling devices at higher temperatures. In addition to this, the coefficient of thermal expansion could be reduced to about $60 \%$ of the value of the unfilled material, even at degrees of filling of $20 \%$ by volume, which is attributed to a non-linear filling effect due to the high fraction of interfaces.

Nanoparticle-based hybrids, however, are of interest also for some other reasons. Due to the high specific surface area of nanoparticles, catalytic properties can be used, too. As known from literature [33], alkoxides from alumina, zirkonia and titania under certain circumstances are able to catalyze the formation of polyethylene oxide type of polymers from epoxides. Whereas zirkonia alkoxides are very active in the catalysis of this reaction, alumina only shows activity at higher temperatures. It was of interest to investigate how far boehmite also can be used for this purpose. This consideration is of practical benefit because, as shown elsewhere, boehmite-containing hybrid materials show very high abrasion resistance in form of coatings which, if the boehmite is distributed homogeneously in the matrix, still remains highly transparent. For this reason, coating systems based on epoxysilanes, TEOS with and without boehmite have been prepared, and the abrasion resistance of the systems has been tested as a function of the boehmite content. The details of the experimental are described elsewhere [10]. In order to distribute homogeneously in the hydrolyzed and epoxy TEOS-containing system, it is necessary to surface-modify the boehmite. This was carried out with acidic acid binds to the particle surface by the formation of an ionic bond, which was proven by IR-spectroscopy. As shown elsewhere by NMR-spectroscopy [34], aluminum oxygen silicon bonds are formed on top of the boehmite particles, substituting the surface modification, as also detectable by IRspectroscopy. The $\mathrm{OH}$ groups of the boehmite, however, still are present, because only low temperatures are used so far. The epoxy group of the epoxy silane, as shown in figure 12, still is present after this procedure. But after curing to temperatures of above $120^{\circ} \mathrm{C}$, the epoxy groupings disappear and the scratch resistance increases substantially. This is not the case in the systems where no boehmite is present. The whole process is shown in figure 12. As a result of the catalytic process of the boehmite nanoparticles, one can see that very high abrasion resistances are obtained. This system has been developed for the application of scratch-resistant coatings on plastics like PMMA, polycarbonate and CR39. It is already in commercial use at a series of products. 


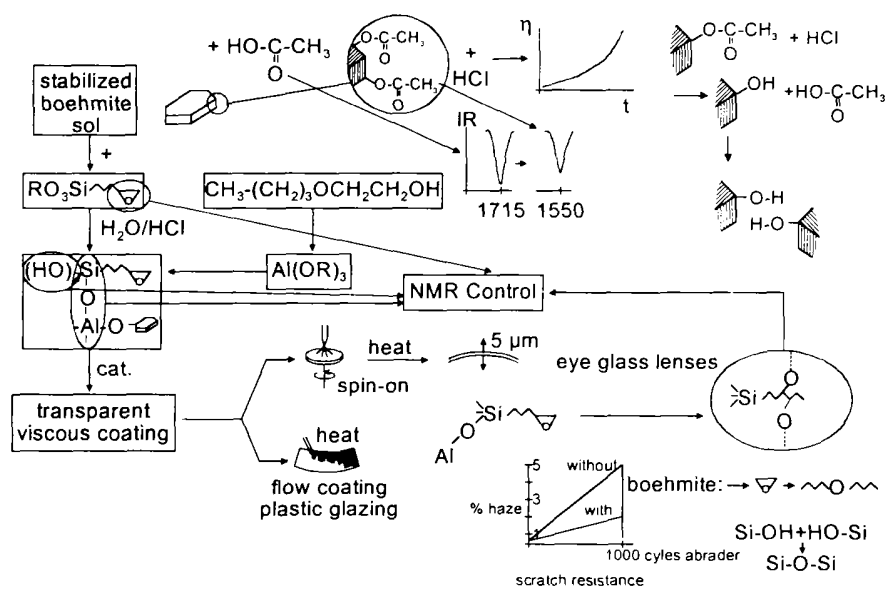

very high scratch resistance, too.
Fig. 12: Scheme of the fabrication of hard coating nanomers through $\mathrm{AlOOH}$ catalysis.

If methacryloxy silanes are used instead of epoxy silanes, similar systems have been synthesized which can be photocured at rather low temperatures, showing a

\section{CONCLUSION}

From the described results it can be concluded that nanoparticle-based hybrid materials $\left(\right.$ Nanomers $^{\mathbb{B}}$ ) show a series of interesting properties which are not obtainable by the molecular type of composites. In order to process these systems to useful materials, the agglomeration of nanoparticles has to be avoided. For this reason, the $\zeta$-potential, which in most cases has to be used for the stabilization of the nanoparticles, has to be tailored or the interfacial free energy to the matrix has to be a minimum. This can be obtained by an appropriate surface modification of the nanoparticles, and if this approach is used, also nanoparticles can be prepared independently in form of organically modified sols (hybrid sols) and easily mixed with the matrix system as, for example, shown with surface modified boehmite to be introduced into a second type of sol. If the prerequirements for stabilization either by surface free energy minimum or electrostatic stabilization are not fulfilled, precipitation, agglomeration or immediate gelation take place. In addition to this, only low degrees of fillings can be obtained. If these requirements are fulfilled, surprisingly high solid contents (over $60 \%$ by volume) can be obtained, which is in opposition to the state of the art of solid contents of gels and sols. So it is postulated that different level of hybrid materials have to be considered. The lowest level is a molecular hybrid where the working horses are organo-functional silanes. The second level of hybrids are hybrid nanoparticles with the surface modification with organic groupings as an example. And the third level of hybrid materials are hybrid matrices built from hybrid molecules with inorganic nanoparticles dispersed in or linked to the hybrid matrix. The latter type has shown very interesting properties, and this type of hybrid materials is still at its infancy but may play a very important role for many applications in the future.

\section{REFERENCES}

1. H. Schmidt, B. Seiferling, G. Philipp, and K. Deichmann, Development of Organic-Inorganic Hard Coatings by the Sol-Gel Process, in Proc. 3rd International Conference on 
Ultrastructure Processing of Advanced Ceramics, edited by J. D. Mackenzie, (Wiley-Interscience, San Diego, CA, 1987), p. 651 - 660

2. R. Reisfeld, Theory and application of spectroscopically active glasses prepared by the solgel method, in Sol-Gel optics. SPIE Int. Symp. of Optical and Optoelectronic Tech., edited by J. D. Mackenzie (SPIE, Bellingham, San Diego, 1990), p. 29-39

3. J. C. Altman, R. E. Stone, F. Nishida, and B. Dunn, Dye Activated ORMOSILs for Lasers and Optical Amplifiers, in Proc. SPIE Int. Soc. Opt. Eng. 1758, Sol-Gel Opt. II, edited by by J. D. Mackenzie (SPIE, Bellingham, San Diego, 1992) p. 507-518

4. L. Hou, B. Hoffmann, M. Mennig, and H. Schmidt, Preparation and Photochromic Properties of Dye-Doped Aluminosilicate and ORMOCER Gels and Coatings J. Sol-Gel Sci. Tech. 2, p. 635-639 (1994).

5. L. Hou and H. Schmidt, Photochromic Properties of a Silylated Spirooxazine in Sol-Gel Coatings, Materials letters 27, p. 215-218 (1996).

6. S. J. Kramer, J. D. Mackenzie, Thermal Stability Enhancement of Rubbery ORMOSILS in Better Ceramics through Chemistry VI, edited by A. K. Cheetham (Mat. Res. Soc. Symp. Proc. 346, Pittsburgh/PA, 1994), p. 709-14.

7. H. Schmidt, Organically Modified Ceramics, Materials with "History" or "Future"?, in Ultrastructure Processing of Advanced Materials, edited by D. R. Uhlmann and D. R. Ulrich (John Wiley and Sons, New York, 1992), p. 409 - 423.

8. W. C. LaCourse, Continous Filament Fibers by the Sol-Gel Process, in: Sol-Gel Technology for Thin Films, Fibers, Preforms, Electronics and Ppecialty Shapes, edited by L. C. Klein, (Noyes Publications, Park Ridge, 1988), p. 184 -197.

9. M. Chatry, M. Henry, M. In, C. Sanchez and J. Livage, The Role of Complexing Ligands in the Formation of Non-Aggregated Nanoparticles of Zirconia, J. Sol-Gel Sci. Technol., 1(3), p. 233-40 (1994).

10. R. Kasemann, H. Schmidt and E. Wintrich, in Titel Better Ceramics Through Chemistry VI, edited by A. K. Cheetham (Mat. Res. Soc. Symp. Proc. 346, Pittsburgh/PA, 1994), p. $915-921$.

11. B. Wang and G. L. Wilkes, Preparation and Uses of High-Refractive-Index Ceramic-Polymer Hybrid Materials, PCT Int. Appl., Virginia Tech Intellectual Properties, Inc., 1991, pp. 17.

12. B. Wang and G. L. Wilkes, High Abrasion-Resistance Coating Materials from OrganicInorganic Hybrid Materials Produced by the Sol-Gel Method, Virginia Tech Intellectual Properties, Inc., 1994, pp. 8.

13. J. E. Mark, The Sol-Gel Route to Inorganic-Organic Composites, Heterog. Chem. Rev. 3(4), p. 307-326 (1996).

14. C. Y. Li, J .Y. Tseng, C. Lechner, J. D. Mackenzie, Preparation of Metal-Cluster-Ormosil Nanocomposites, in Chemical Processes in Inorganic Materials: Metal and Semiconductor Clusters and Colloids (Mat. Res. Soc. Symp. Proc. 272, Pittsburgh/PA, 1992), p. 133-138.

15. H. Schmidt, KONA Powder and Particle, 14, p. 92 - 103 (1996).

16. O. Stern, Z. Elektrochem. p. 508 (1924).

17. R. Nonninger, to be published later.

18. H. Schmidt, E. Arpac, H. Schirra, S. Sepeur and G. Jonschker, Aqueous Sol-Gel Derived Nanocomposite Coating Materials, in Organic/Inorganic Hybrid Materials, edited by R. M. Laine (Mat. Res. Soc. Symp. Proc. 519, Pittsburgh/PA, 1998), p. 297 - 308.

19. M. X. Tang, F. C. Szoka, The influence of polymer structure on the interactions of cationic polymers with DNA and morphology of the resulting complexes, Gene Therapy, 4, p. 823 832 (1997). 
20. T. Schiestel, H. Schirra, J. Gerwann, C. Lesniak, A. Kalaghi-Nafchi, M. Sameti, G. Borchard, E. Haltner, C.-M. Lehr and H. Schmidt, in Biomaterials Regulating Cell Function and Tissue Development, edited by R. C. Thomson (Mat. Res. Soc. Symp. Proc. 530, Pittsburgh/PA, 1998), p. 65-71.

21. C. Kneuer, M. Sameti, E. Haltner, T. Schiestel, H. Schirra, H. Schmidt, and C.-M. Lehr, New Materials for Gene Delivery: Surface-Modified Silica Nanoparticles can Efficiently Bind, Protect and Transfect Genes In-Vitro, Poster: CRS Annual Meeting, Erlangen, Germany, 18.-19.03.99.

22. R. Nass, M. Aslan, R. Nonninger, H. Schmidt, P. Matje, New Processing Techniques for the Production of Pressureless Sintered SiC Parts, in Ceramic Processing Science and Technology, edited by Hausner (ACerS. 51, Westerville, 1995) p. 433-437.

23. R. Nonninger, Ph. D. Thesis, University of Saarland, Saarbrücken, Germany, 1995.

24. P. Judeinstein, P. W. Oliveira, H. Krug, and H. Schmidt, Photochromic Organic-Inorganic Nanocomposites as Holographic Storage Media, Adv. Mater. Opt. Electron. 7(3), p. 123133 (1997).

25. P. W. Oliveira, H. Krug, P. Müller, and H. Schmidt, Fabrication of GRIN-Materials by Photopolymerization of Diffusion-Controlled Organic-Inorganic Nanocomposite Materials, in Better Ceramics Through Chemistry VII : Organic/Inorganic Hybrid Materials, edited by B. K. Coltrain (Mat. Res. Soc. Proc. 435, Pittsburgh, PA 1996) p. 5553-5558.

26. P. W. Oliveira, H. Krug, A. Frantzen, M. Mennig, M., and H. Schmidt, Generation of Wet-Chemical AR-Coatings on Plastic Substrates by Use of Polymerizable Nanoparticles, in SPIE Vol. 3136 Sol-Gel Optics IV, edited by J. D. Mackenzie (SPIE, Bellingham/ Washington, 1997), p. 452-461.

27. F. Tiefensee, Ph. D. Thesis, University of Saarland, Saarbrücken, Germany, 1994.

28. P. W. Oliveira, private communication, to be published later.

29. M. Mennig, P. W. Oliveira, H. Schmidt, Interference Coatings on Glass Based on Photopolymerizable Nanomer Material, Proc. $2^{\text {nd }}$ ICCG (1998), Saarbrücken, accepted for publication in Thin Solid Films (in print).

30. P. W. Oliveira, H. Krug, A., Frantzen, M., Mennig, H., Schmidt, Multilayer NIR Reflective Coatings on Transparent Plastic Substrates from Photopolymerizable Nanoparticulate Sols, Proc. $2^{\text {nd }}$ ICCG (1998), Saarbrücken, accepted for publication in Thin Solid Films (in print).

31. M. Mennig, P. W. Oliveira, and H. Schmidt, to be held at MRS Spring Meeting 1999, San Francisco/CA, USA.

32. T. Koch, M., Mennig, and H. Schmidt, UV-Curable Epoxy-Based Nanocomposite Adhesive for Applications in Integrated Optics, World Ceramics Congress \& Forum on New Materials (CIMTEC), Florence/Italy, 1998 (in print)

33. G. Philipp and H. Schmidt, The Reactivities of $\mathrm{TiO}_{2}$ and $\mathrm{ZrO}_{2}$ in Organically Modified Silicates, J. Non-Cryst. Sol. 82, p. 31-36 (1986).

34. H. Schmidt, R. Kasemann, T. Burkhart, G. Wagner, E. Arpac, and E. Geiter, InorganicOrganic Hybrid Coatings for Metal and Glass Surfaces, in Hybrid Organic-Inorganic Composites, edited by J. E. Mark (American Chemical Society, ACS 585, Washington, DC, 1994), p. 331-347. 